\title{
Hippophae rhamnoides L. Fruits Reduce the Oxidative Stress in Human Blood Platelets and Plasma
}

\author{
Beata Olas, ${ }^{1}$ Bogdan Kontek, ${ }^{1}$ Paulina Malinowska, ${ }^{1}$ \\ Jerzy Żuchowski, ${ }^{2}$ and Anna Stochmal ${ }^{2}$ \\ ${ }^{1}$ Department of General Biochemistry, Faculty of Biology and Environmental Protection, University of Łódź, 90-236 Łódź, Poland \\ ${ }^{2}$ Department of Biochemistry, Institute of Soil Science and Plant Cultivation, State Research Institute, 24-100 Puławy, Poland
}

Correspondence should be addressed to Beata Olas; olasb@biol.uni.lodz.pl

Received 18 September 2015; Revised 23 November 2015; Accepted 25 November 2015

Academic Editor: Rosa Tundis

Copyright (C) 2016 Beata Olas et al. This is an open access article distributed under the Creative Commons Attribution License, which permits unrestricted use, distribution, and reproduction in any medium, provided the original work is properly cited.

\begin{abstract}
Effects of the phenolic fraction from Hippophae rhamnoides fruits on the production of thiobarbituric acid reactive substances (TBARS, a marker of lipid peroxidation) and the generation of superoxide anion $\left(\mathrm{O}_{2}{ }^{-}\right)$in human blood platelets (resting platelets and platelets stimulated by a strong physiological agonist, thrombin) were studied in vitro. We also examined antioxidant properties of this fraction against human plasma lipid peroxidation and protein carbonylation induced by a strong biological oxidant, hydrogen peroxide $\left(\mathrm{H}_{2} \mathrm{O}_{2}\right)$ or $\mathrm{H}_{2} \mathrm{O}_{2} / \mathrm{Fe}$ (a donor of hydroxyl radicals). The tested fraction of $H$. rhamnoides $(0.5-50 \mu \mathrm{g} / \mathrm{mL}$; the incubation time: 15 and $60 \mathrm{~min}$ ) inhibited lipid peroxidation induced by $\mathrm{H}_{2} \mathrm{O}_{2}$ or $\mathrm{H}_{2} \mathrm{O}_{2} /$ Fe. The $H$. rhamnoides phenolic fraction inhibited not only plasma lipid peroxidation, but also plasma protein carbonylation stimulated by $\mathrm{H}_{2} \mathrm{O}_{2}$ or $\mathrm{H}_{2} \mathrm{O}_{2} / \mathrm{Fe}$. Moreover, the level of $\mathrm{O}_{2}{ }^{-\bullet}$ in platelets significantly decreased. In comparative experiments, the $H$. rhamnoides fraction was a more effective antioxidant than aronia extract or grape seed extract (at the highest tested concentration, $50 \mu \mathrm{g} / \mathrm{mL}$ ). The obtained results suggest that $H$. rhamnoides fruits may be a new, promising source of natural compounds with antioxidant and antiplatelet activity beneficial not only for healthy people, but also for those with oxidative stress-associated diseases.
\end{abstract}

\section{Introduction}

Hippophae rhamnoides L. (sea buckthorn), naturally occurring throughout Asia and Europe, is a member of the Elaeagnaceae family [1]. Due to its multiple biological properties (anticancer, antimicrobial, and cardioprotective) [1-6], $H$. rhamnoides has been used in traditional medicine for a long time $[1,7,8]$. This plant has been used extensively in traditional oriental system of medicine for treatment of asthma, skin diseases, lung disorders, and gastric ulcers. All parts of $H$. rhamnoides, including fruits, are considered to be a rich source of different bioactive compounds $[5,6$, 9]. It contains phenolic compounds, lipids, and vitamin C; phenolics are responsible for its pharmacological activity $[1,5$, $8,10]$. Moreover, dietary intake of phenolic compounds may be viewed as an important strategy for treating pathological conditions or delaying their development, as well as a chance for disease prevention in many paradigms. Experiments of Eccleston et al. [11] reported that the fruit juice of $H$. rhamnoides had a protective effect against cardiovascular diseases, but the mechanism is not fully clear as yet. It is very important that $H$. rhamnoides is one of the most representative economy crops for its wide uses of biological diversity and abundance of resource [12].

In this study, we focused on fruits of $H$. rhamnoides, which might be of great interest. The objective was to investigate the antioxidant activity of the phenolic fraction from $H$. rhamnoides fruits against the effect of a strong biological oxidant, hydrogen peroxide $\left(\mathrm{H}_{2} \mathrm{O}_{2}\right)$ or $\mathrm{H}_{2} \mathrm{O}_{2} / \mathrm{Fe}$ (the donor of hydroxyl radicals), on human plasma lipids and proteins. Moreover, we determined the effect of the phenolic extract on a nonenzymatic lipid peroxidation in resting blood platelets and enzymatic lipid peroxidation, arachidonic acid metabolism (measured by the level of thiobarbituric acid reactive substances (TBARS)), in blood platelets activated by thrombin (as a strong physiological agonist). We also investigated the in vitro effect of the tested fraction on the superoxide anion $\left(\mathrm{O}_{2}{ }^{-\bullet}\right)$ production in resting blood platelets 
and platelets activated by thrombin. Experimental models used in this study were similar to reactions which take place in human plasma and blood platelets under oxidative stress conditions or during a blood platelet activation. Moreover, blood platelets and their activation are important in hemostasis, and in various diseases, that is, cardiovascular diseases. The action of the fraction from $H$. rhamnoides fruits was also compared to activities of two phenolic extracts: a commercial extract from the berries of Aronia melanocarpa (Aronox) and a grape seed extract with antioxidative and antiplatelet properties [13-15]. The range of tested concentrations of the $H$. rhamnoides fraction $(0.5-50 \mu \mathrm{g} / \mathrm{mL})$ or the other two extracts $(50 \mu \mathrm{g} / \mathrm{mL})$ can be achieved in plasma by way of supplementation with phenolic compounds.

\section{Material and Methods}

2.1. Chemicals. Cytochrome c, dimethylsulfoxide (DMSO), thiobarbituric acid (TBA), $\mathrm{H}_{2} \mathrm{O}_{2}$, and formic acid (LC-MS grade) were purchased from Sigma (St. Louis, MO., USA). Methanol (isocratic grade) and acetonitrile (LC-MS grade) were acquired from Merck (Darmstadt, Germany). All other reagents represented analytical grade and were provided by commercial suppliers.

A stock solution of A. melanocarpa extract (commercial product, Aronox, by Agropharm Ltd., Poland; batch number 020/2007k) was made in $\mathrm{H}_{2} \mathrm{O}$ at a concentration of $5 \mathrm{mg} / \mathrm{mL}$, kept frozen, and then used for experiments. Total content of phenolics in the phenolic-rich powder used in this study amounted to $309.6 \mathrm{mg} / \mathrm{g}$ of extract, including phenolic acids (isomers of chlorogenic acid), $149.2 \mathrm{mg} / \mathrm{g}$ of extract, anthocyanins (anthocyanin glycosides: cyanidin 3-galactoside, cyanidin 3-glucoside, cyanidin 3-arabinoside, and cyanidin 3-xyloside), $110.7 \mathrm{mg} / \mathrm{g}$, and flavonoids (quercetin glycosides), $49.7 \mathrm{mg} / \mathrm{g}$ of extract. The HPLC determination of the phenolic-rich extract from berries of A. melanocarpa was described previously [13-15].

The grape seed extract was supplied by Bionorica (Germany) with a total content of phenolics equalling $500 \mathrm{mg} / \mathrm{g}$ of extract [15]. A stock solution of grape seed extract was prepared in 50\% DMSO.

2.2. Plant Material. Sea buckthorn (Hippophae rhamnoides L.) berries were obtained from a horticultural farm in Sokółka, Podlaskie Voivodeship, Poland $\left(53^{\circ} 24^{\prime} \mathrm{N}, 23^{\circ} 30^{\prime} \mathrm{E}\right)$. Fruits were freeze-dried and stored in a refrigerator.

\subsection{Preparation of the Fraction of Phenolic Compounds.} Freeze-dried sea buckthorn fruits $(800 \mathrm{~g})$ were subjected to cold extraction with $4 \mathrm{~L}$ of $80 \%$ methanol (v/v; $24 \mathrm{~h}$ ), assisted with ultrasonic treatment $(2 \times 10 \mathrm{~min})$. The plant material was further extracted with boiling $80 \%$ methanol (v/v; $4 \mathrm{~L}$; $1 \mathrm{~h}$ ), under reflux. Both extracts were combined, filtered, and concentrated in a rotary evaporator (Heidolph, Schwabach, Germany) to remove the organic solvent. The residue was applied onto a short LiChroprep 40-63 $\mu \mathrm{m}$ RP-18 column (Millipore Corp., Bedford, MA) and equilibrated with water. The column was washed with water to remove highly polar extract constituents, and bound phenolic compounds were eluted with $50 \%$ methanol (v/v). The obtained 50\% methanol eluate was concentrated by a rotary evaporation and subsequently freeze-dried, to yield $10.19 \mathrm{~g}$ of dry phenolic fraction.

2.4. LC-MS Analysis. The composition of the phenolic fraction of sea buckthorn fruits was determined using an HPLCESI-MS/MS method. Chromatographic analyses were carried out with the application of a Thermo Finnigan Surveyor HPLC system, equipped with a PDA detector and coupled with a Thermo LCQ Advantage Max ion-trap mass spectrometer. Separation was performed on a Waters XBridge $\mathrm{BEH}$ $\mathrm{C} 18$ column $(3.0 \times 150 \mathrm{~mm}, 2.5 \mu \mathrm{m})$, maintained at $50^{\circ} \mathrm{C}$. The injection volume was $5 \mu \mathrm{L}$. The elution $\left(300 \mu \mathrm{L} \mathrm{min}^{-1}\right)$ was carried out with a gradient of solvent B (acetonitrile with $0.1 \% \mathrm{FA}$ ) in solvent A (MilliQ water with $0.1 \% \mathrm{FA}$ ): $0-5 \mathrm{~min}$, $5 \% \mathrm{~B}$; 5-85 min, 5-60\% B; $85-95 \mathrm{~min}, 60 \% \mathrm{~B}$. The UV-Vis spectra were recorded from 200 to $600 \mathrm{~nm}$. Mass spectral analyses were performed in the negative ionization mode with the following parameters: capillary temperature $260^{\circ} \mathrm{C}$, spray voltage $3.9 \mathrm{kV}$, capillary voltage $-47 \mathrm{~V}$, tube lens offset $-60 \mathrm{~V}$, sheath gas flow 70 (arbitrary units), and sweep gas flow 10 (arbitrary units). The MS scan covered a range from $\mathrm{m} / z 150$ to $\mathrm{m} / \mathrm{z} 2000$; the MS/MS spectra were acquired in the Data-Dependent Analysis (DDA) mode. Flavonoids were identified on the basis of their MS and UV spectra, as well as literature data $[16,17]$.

Quantitative analyses were carried out using UHPLCUV-MS method. Chromatographic separations were performed on an ACQUITY UPLC chromatograph, consisting of a binary solvent manager, autosampler, column manager, and photodiode array detector (Waters, Milford, MA, USA), and coupled with a triple quadrupole mass detector (ACQUITY TQD, Waters). Samples were separated on an ACQUITY HSS C18 $(100 \times 2.1 \mathrm{~mm}, 1.8 \mu \mathrm{m}$; Waters $)$ column and maintained at $40^{\circ} \mathrm{C}$. The injection volume was $2.5 \mu \mathrm{L}$. The elution $\left(400 \mu \mathrm{L} \mathrm{min}^{-1}\right)$ was carried out with a gradient of solvent B (acetonitrile with $0.1 \% \mathrm{FA}$ ) in solvent A (MilliQ water with $0.1 \% \mathrm{FA}$ ): $0-0.50 \mathrm{~min}, 1 \% \mathrm{~B} ; 0.50-17.95 \mathrm{~min}, 1-$ $35.5 \%$ B; $17.95-18.00 \mathrm{~min}, 35.5-99 \%$ B; $18.00-20.00 \mathrm{~min}, 99 \%$ B. Capillary voltage amounted to $3.0 \mathrm{kV}$, cone voltage $40 \mathrm{~V}$, source temperature $140^{\circ} \mathrm{C}$, desolvation temperature $350^{\circ} \mathrm{C}$, cone gas flow (nitrogen) $100 \mathrm{~L} \mathrm{~h}^{-1}$, and desolvation gas flow $800 \mathrm{Lh}^{-1}$. PDA detection was used for the quantitation of phenolic compounds ( $\lambda=350 \mathrm{~nm}$ for flavonoids, $254 \mathrm{~nm}$ for other phenolics). Since isorhamnetin derivatives are the main flavonoids found in sea buckthorn fruits, the standard curve of isorhamnetin 3 - $O$ - $\beta$-glucosyl $(1 \rightarrow 2)$ - $\beta$-galactoside was applied to calculate relative concentrations of individual flavonoids and the total content of other phenolic compounds. Analyses were performed in triplicate.

A stock solution of the investigated plant fraction was made in 50\% DMSO. The final concentration of DMSO in samples was lower than $0.05 \%$ and its effects were determined in all experiments.

2.5. Blood Platelet and Plasma Isolation. Fresh human plasma was obtained from regular, medication-free donors at a blood bank (Łódź, Poland). Peripheral blood was also obtained from nonsmoking men and women (collected into ACD 
solution (citric acid/citrate/dextrose; 5 : 1; v/v; blood/ACD)). They had not taken any medications or addictive substances (including tobacco, alcohol, antioxidant supplementation, aspirin, or any other antiplatelet drugs). The protocol was approved by the Committee for Research on Human Subjects of the University of Łódź number 2/KBBN-UŁ/III/2014. Platelet-rich plasma (PRP) was prepared by centrifugation of fresh human blood at $250 \times \mathrm{g}$ for $10 \mathrm{~min}$ at room temperature. Platelets were then sedimented by centrifugation at $500 \times \mathrm{g}$ for $10 \mathrm{~min}$ at room temperature. The platelet pellet was washed twice with Tyrode's buffer (10 mM HEPES, $140 \mathrm{mM} \mathrm{NaCl}$, $3 \mathrm{mM} \mathrm{KCl}, 0.5 \mathrm{mM} \mathrm{MgCl}_{2}, 5 \mathrm{mM} \mathrm{NaHCO}_{3}, 10 \mathrm{mM}$ glucose, $\mathrm{pH}$ 7.4); afterwards, the platelets were suspended in the same buffer. The concentration of platelets in suspensions, estimated spectrophotometrically [18], amounted to $5 \times$ $10^{8} / \mathrm{mL}$.

Suspensions of blood platelets or plasma were incubated $\left(15\right.$ or $60 \mathrm{~min}$, at $37^{\circ} \mathrm{C}$ ) with

(i) $H$. rhamnoides fraction at the final concentrations of $0.5-50 \mu \mathrm{g} / \mathrm{mL}$,

(ii) H. rhamnoides fraction at the final concentrations of $0.5-50 \mu \mathrm{g} / \mathrm{mL}$ plus $2 \mathrm{mM} \mathrm{H}_{2} \mathrm{O}_{2}$,

(iii) $H$. rhamnoides fraction at the final concentrations of $0.5-50 \mu \mathrm{g} / \mathrm{mL}$ plus $4.7 \mathrm{mM} \mathrm{H}_{2} \mathrm{O}_{2} / 3.8 \mathrm{mM}$ $\mathrm{Fe}_{2} \mathrm{SO}_{4} / 2.5 \mathrm{mM}$ EDTA,

(iv) $\mathrm{H}$. rhamnoides fraction at the final concentrations of $0.5-50 \mu \mathrm{g} / \mathrm{mL}$ plus $5 \mathrm{U} / \mathrm{mL}$ thrombin $\left(5 \mathrm{~min}\right.$, at $\left.37^{\circ} \mathrm{C}\right)$,

(v) Aronia extract or grape seed extract at the final concentration of $50 \mu \mathrm{g} / \mathrm{mL}$,

(vi) Aronia extract or grape seed extract at the final concentration of $50 \mu \mathrm{g} / \mathrm{mL}$ plus $2 \mathrm{mM} \mathrm{H}_{2} \mathrm{O}_{2}$,

(vii) Aronia extract or grape seed extract at the final concentration of $50 \mu \mathrm{g} / \mathrm{mL}$ plus $4.7 \mathrm{mM} \mathrm{H}_{2} \mathrm{O}_{2} / 3.8 \mathrm{mM}$ $\mathrm{Fe}_{2} \mathrm{SO}_{4} / 2.5 \mathrm{mM}$ EDTA,

(viii) Aronia extract or grape seed extract at the final concentration of $50 \mu \mathrm{g} / \mathrm{mL}$ plus $5 \mathrm{U} / \mathrm{mL}$ thrombin $\left(5 \mathrm{~min}\right.$, at $\left.37^{\circ} \mathrm{C}\right)$.

2.6. Lipid Peroxidation Measurement. Lipid peroxidation was quantified by measuring the concentration of TBARS. Incubation of plasma or blood platelets (control, plant extract and $\mathrm{H}_{2} \mathrm{O}_{2}$ - or $\mathrm{H}_{2} \mathrm{O}_{2} / \mathrm{Fe}$-treated plasma, plant extract, and thrombin-treated platelets) was stopped by cooling the samples in an ice bath. Samples of plasma or platelets were transferred to an equal volume of cold $20 \%(\mathrm{v} / \mathrm{v})$ trichloroacetic acid in $0.6 \mathrm{M} \mathrm{HCl}$ and centrifuged at $1200 \times \mathrm{g}$ for $15 \mathrm{~min}$. One volume of clear supernatant was mixed with 0.2 volume of $0.12 \mathrm{M}$ thiobarbituric acid in $0.26 \mathrm{M}$ Tris $(\mathrm{pH}$ 7.0), immersed in a boiling water bath for $15 \mathrm{~min}$, and then absorbance was measured at $532 \mathrm{~nm}$ (Spectrophotometer UV/Vis Helios alpha Unicam) $[19,20]$. The TBARS concentration was calculated using the molar extinction coefficient $\left(\varepsilon=156,000 \mathrm{M}^{-1} \mathrm{~cm}^{-1}\right)$.

2.7. Superoxide Anion Measurement. Cytochrome c reduction was used to measure $\mathrm{O}_{2}{ }^{-\bullet}$ generation in control and in
TABLE 1: Content of flavonol glycosides in the phenolic fraction of sea buckthorn fruits.

\begin{tabular}{lccc}
\hline & $t_{R}$ & {$[\mathrm{M}-\mathrm{H}]^{-}$} & $\mathrm{mg} / \mathrm{g} \pm \mathrm{SD}$ \\
\hline Quercetin 3-O-Hex-Hex-7-O-dHex & 6.62 & 771 & $2.03 \pm 0.02$ \\
Quercetin 3-O-Hex-Hex-7-O-dHex & 6.75 & 771 & $8.13 \pm 0.05$ \\
Kaempferol 3-O-Hex-Hex-dHex & 7.07 & 755 & $0.99 \pm 0.19$ \\
Kaempferol 3-O-Hex-Hex-dHex & 7.23 & 755 & $9.45 \pm 0.07$ \\
Isorhamnetin 3-O-Hex-Hex-dHex & 7.53 & 785 & $3.86 \pm 0.00$ \\
Isorhamnetin 3-O-Hex-Hex-dHex & 7.59 & 785 & $15.36 \pm 0.27$ \\
Quercetin 3-O-Hex-7-O-dHex & 8.14 & 609 & $3.38 \pm 0.04$ \\
Quercetin 3-O-Hex-dHex-dHex & 8.20 & 755 & $5.62 \pm 0.04$ \\
Quercetin 3-O-Hex-dHex & 9.17 & 609 & $10.00 \pm 0.10$ \\
Isorhamnetin 3-O-Hex-7-O-dHex & 9.26 & 623 & $33.57 \pm 0.14$ \\
Quercetin 3-O-Hex & 9.46 & 463 & $25.32 \pm 0.15$ \\
Isorhamnetin 3-O-Hex-dHex & 10.32 & 623 & $3.75 \pm 0.13$ \\
Isorhamnetin 3-O-Hex-dHex & 10.50 & 623 & $44.00 \pm 0.35$ \\
Isorhamnetin 3-O-Hex & 10.85 & 477 & $44.16 \pm 0.08$ \\
Quercetin derivative & 12.00 & 709 & $0.64 \pm 0.01$ \\
Isorhamnetin derivative & 12.95 & 723 & $1.94 \pm 0.13$ \\
Isorhamnetin derivative & 13.76 & 723 & $1.84 \pm 0.02$ \\
Other flavonol glycosides & & & $28.65 \pm 0.94$ \\
\hline Position of sag
\end{tabular}

${ }^{*}$ Position of sugar groups determined on the basis of literature data; Hex: a hexose; dHex: a deoxyhexose.

platelets incubated with the tested compounds, as described earlier [21, 22]. Briefly, an equal volume of modified Tyrode's buffer, containing cytochrome c $(160 \mu \mathrm{M})$, was added to the platelet suspension. After incubation, the platelets were sedimented by centrifugation at $2000 \times \mathrm{g}$ for $5 \mathrm{~min}$ and the supernatants were transferred to cuvettes. Cytochrome c reduction was measured spectrophotometrically at $595 \mathrm{~nm}$. To calculate the molar concentration of $\mathrm{O}_{2}{ }^{-\bullet}$, the molar extinction coefficient for cytochrome $\mathrm{c}$ of $18,700 \mathrm{M}^{-1} \mathrm{~cm}^{-1}$ was used.

2.8. Carbonyl Groups Measurement. Detection of carbonyl groups in plasma proteins was carried out according to the procedure of Dalle-Donne et al. [23].

2.9. Data Analysis. Statistical analysis was done using several tests. In order to eliminate uncertain data, the Q-Dixon test was performed. All the values in this study were expressed as mean \pm standard error (SE). Statistical analysis was performed with one-way ANOVA for repeated measurements.

\section{Results}

The LC-MS analyses demonstrated that flavonoids were the dominant compounds in the phenolic fraction of sea buckthorn fruits and their total amount equalled $214.04 \mathrm{mg} / \mathrm{g}$ (Table 1). Among different flavonol glycosides, both isorhamnetin 3-O-hexoside-deoxyhexoside and isorhamnetin 3-Ohexoside were present in the highest amounts. Other phenolic compounds, including putative proanthocyanidins, were hard to identify, and most of them occurred in low 


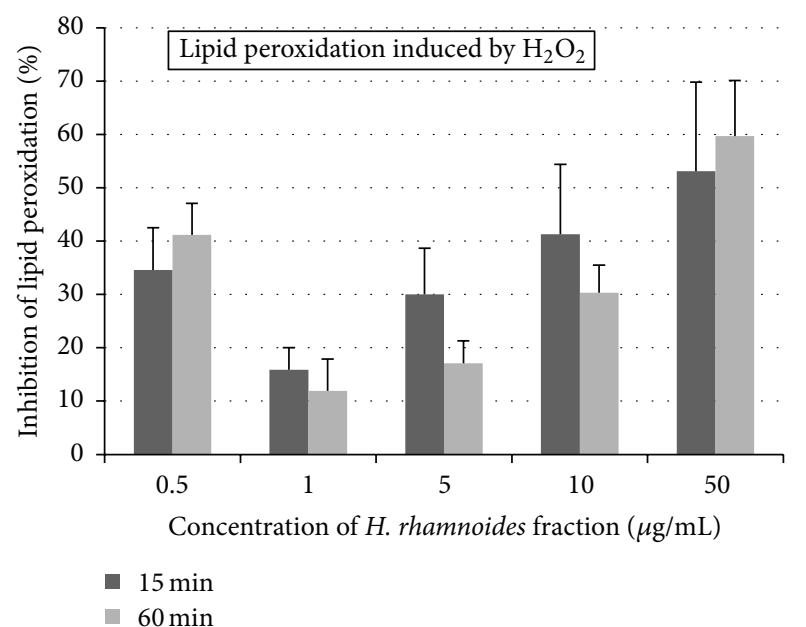

(a)

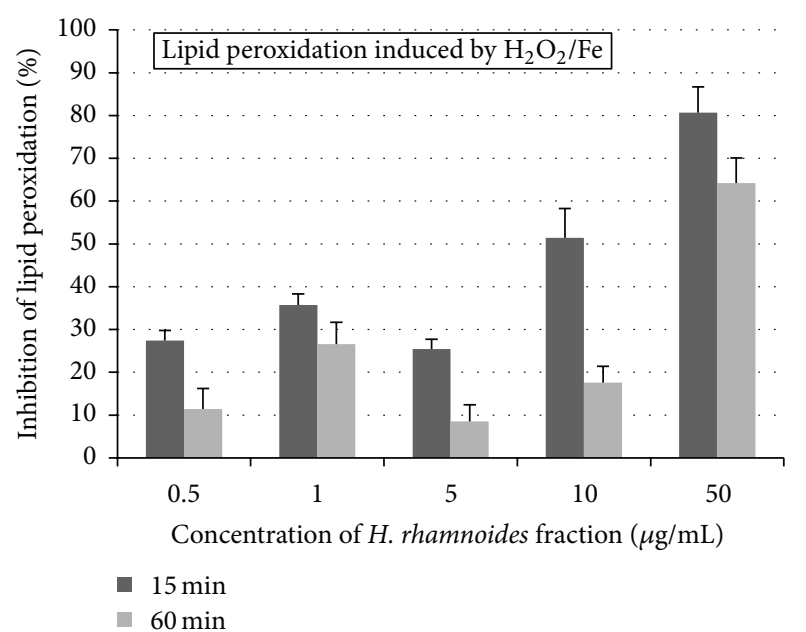

(b)

FIGURE 1: Effects of the phenolic fraction from fruits of $H$. rhamnoides $(0.5-50 \mu \mathrm{g} / \mathrm{mL} ; 15$ and $60 \mathrm{~min})$ on plasma lipid peroxidation induced by $\mathrm{H}_{2} \mathrm{O}_{2}$ (a) and plasma lipid peroxidation induced by $\mathrm{H}_{2} \mathrm{O}_{2} / \mathrm{Fe}$ (b). Data represent means \pm standard error (SE) of 4-5. The effect of five different concentrations of the tested fraction $(0.5,1,5,10$, and $50 \mu \mathrm{g} / \mathrm{mL})$ was statistically significant according to ANOVA $I$ test, $p<0.05$ for concentrations $0.5,5,10$, and $50 \mu \mathrm{g} / \mathrm{mL}$ (for 15 and $60 \mathrm{~min}$ ) (a); $p>0.05$ for concentration $1 \mu \mathrm{g} / \mathrm{mL}$ (for 15 and $60 \mathrm{~min}$ ) (a); $p<0.05$ for concentrations $0.5,1$, and $5 \mu \mathrm{g} / \mathrm{mL}$ (for $15 \mathrm{~min}$ ) (b); $p<0.02$ for concentrations 10 and $50 \mu \mathrm{g} / \mathrm{mL}$ (for $15 \mathrm{~min}$ ) (b); $p<0.02$ for concentration $50 \mu \mathrm{g} / \mathrm{mL}$ (for $60 \mathrm{~min}$ ) (b); $p>0.05$ for concentrations $0.5,1,5$, and $10 \mu \mathrm{g} / \mathrm{mL}$ (for $60 \mathrm{~min}$ ) (b).

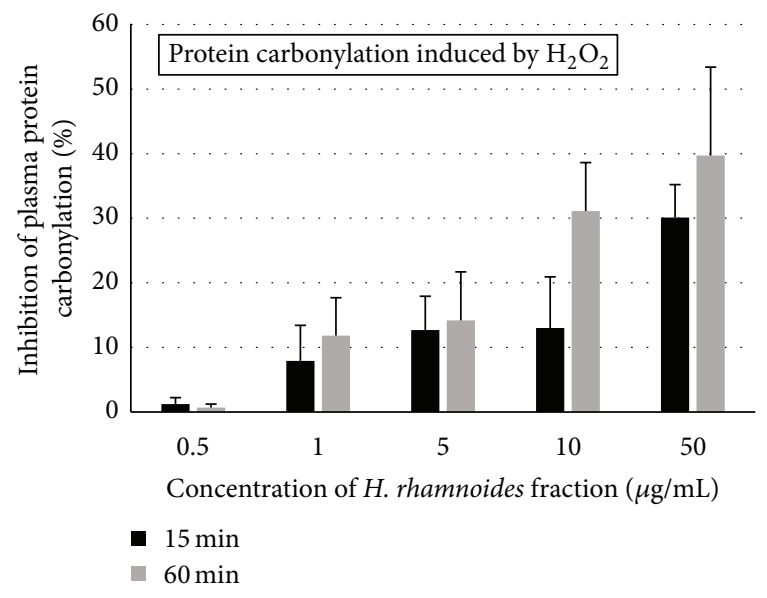

(a)

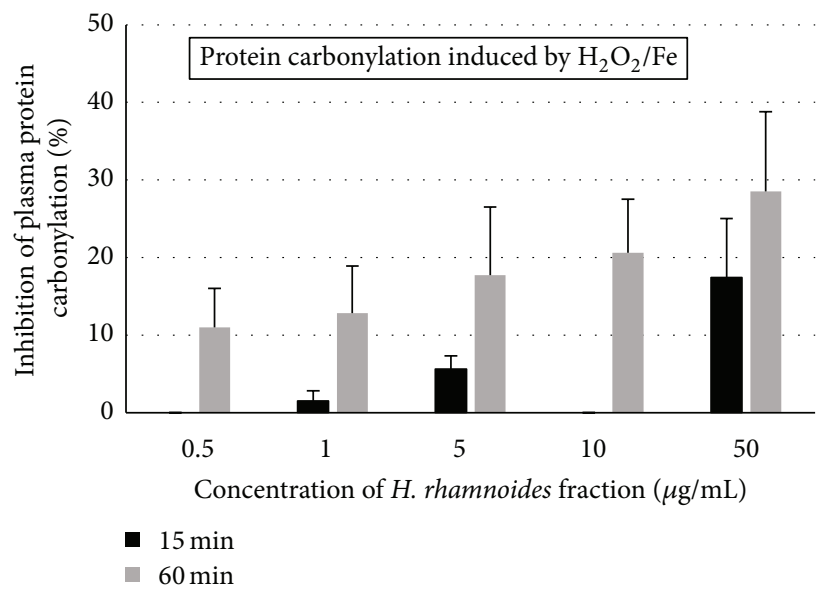

(b)

FiguRE 2: Effects of the phenolic fraction from fruits of $H$. rhamnoides $(0.5-50 \mu \mathrm{g} / \mathrm{mL} ; 15$ and $60 \mathrm{~min})$ on plasma protein carbonylation induced by $\mathrm{H}_{2} \mathrm{O}_{2}$ (a) and plasma protein carbonylation induced by $\mathrm{H}_{2} \mathrm{O}_{2} / \mathrm{Fe}$ (b). Data represent means \pm standard error (SE) of 4 . The effect of five different concentrations of the tested fraction $(0.5,1,5,10$, and $50 \mu \mathrm{g} / \mathrm{mL})$ was statistically significant according to ANOVA $I$ test, $p<0.05$ for concentration $50 \mu \mathrm{g} / \mathrm{mL}$ (for $15 \mathrm{~min}$ ) (a); $p<0.05$ for concentrations 10 and $50 \mu \mathrm{g} / \mathrm{mL}$ (for $60 \mathrm{~min}$ ) (a); $p>0.05$ for concentrations $0.5,1$, 5 , and $10 \mu \mathrm{g} / \mathrm{mL}$ (for $15 \mathrm{~min}$ ) (a); $p>0.05$ for concentrations $0.5,1$, and $5 \mu \mathrm{g} / \mathrm{mL}$ (for $60 \mathrm{~min}$ ) (a); $p<0.05$ for concentration $50 \mu \mathrm{g} / \mathrm{mL}$ (for $15 \mathrm{~min}$ ) (b); $p<0.05$ for concentrations 5,10 , and $50 \mu \mathrm{g} / \mathrm{mL}$ (for $60 \mathrm{~min}$ ) (b); $p>0.05$ for concentrations $0.5,1,5$, and $10 \mu \mathrm{g} / \mathrm{mL}$ (for $15 \mathrm{~min}$ ) (b); $p>0.05$ for concentrations 0.5 and $1 \mu \mathrm{g} / \mathrm{mL}$ (for $60 \mathrm{~min}$ ) (b).

concentrations. Their total content measured $28.65 \mathrm{mg} / \mathrm{g}$ (expressed as isorhamnetin $3-O-G l c(1 \rightarrow 2)$-Gal equivalent).

The antioxidative activities of the phenolic fraction from $H$. rhamnoides fruits (at a dose range $0.5-50 \mu \mathrm{g} / \mathrm{mL}$; incubation time: 15 and $60 \mathrm{~min}$ ) were studied in vitro. As demonstrated in Figures 1 and 2, the tested fraction inhibited plasma lipid peroxidation and protein carbonylation stimulated by $\mathrm{H}_{2} \mathrm{O}_{2}$ or $\mathrm{H}_{2} \mathrm{O}_{2} / \mathrm{Fe}$. The inhibition of lipid peroxidation in plasma reached about $60 \%$ when the highest concentration
$(50 \mu \mathrm{g} / \mathrm{mL})$ of the fraction and the longest incubation time (60 min) were applied (Figures 1(a) and 1(b)).

Another set of experiments focused on the determination of TBARS levels as a measure of nonenzymatic lipid peroxidation in resting blood platelets and enzymatical peroxidation of arachidonic acid in blood platelets stimulated by thrombin. After a 15 min preincubation of platelets with the H. rhamnoides phenolic fraction, the amount of TBARS in resting platelets and thrombin-activated platelets diminished. 


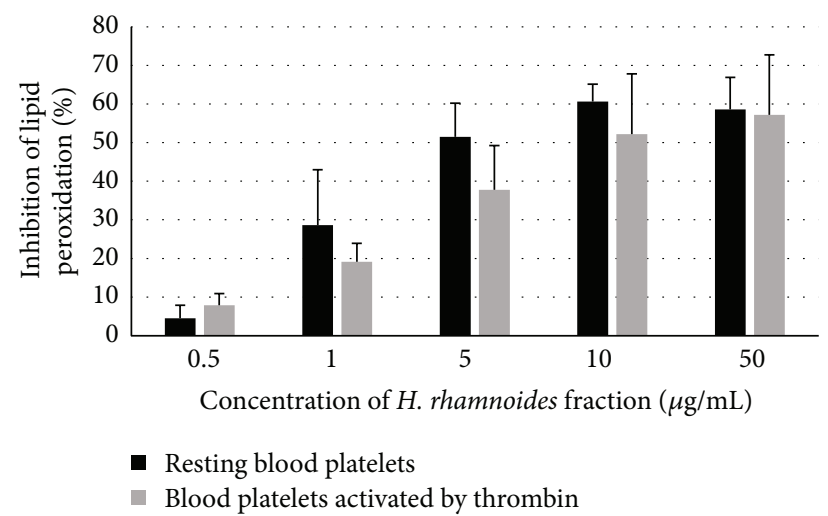

Figure 3: Effects of the phenolic fraction from fruits of $H$. rhamnoides $(0.5-50 \mu \mathrm{g} / \mathrm{mL} ; 15 \mathrm{~min})$ on lipid peroxidation in resting blood platelets and blood platelets activated by thrombin. Data represent means of 3-4 donors \pm standard error (SE). The effect of five different concentrations of the tested fraction $(0.5,1,5,10$, and $50 \mu \mathrm{g} / \mathrm{mL})$ was statistically significant according to ANOVA $I$ test, $p<0.05$ for concentrations $1,5,10$, and $50 \mu \mathrm{g} / \mathrm{mL} ; p>0.05$ for concentration $0.5 \mu \mathrm{g} / \mathrm{mL}$.

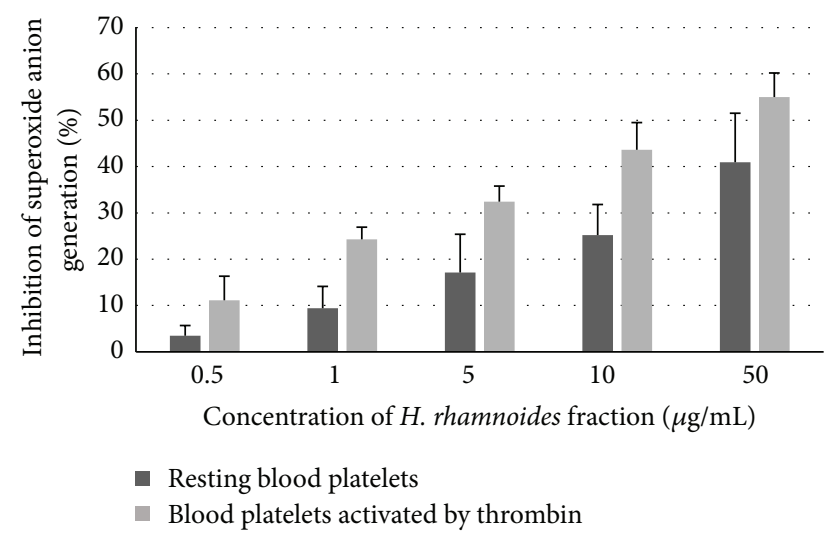

FIgURE 4: Effects of the phenolic fraction from fruits of $H$. rhamnoides $(0.5-50 \mu \mathrm{g} / \mathrm{mL} ; 15 \mathrm{~min})$ on $\mathrm{O}_{2}{ }^{-\bullet}$ generation in resting blood platelets and blood platelets activated by thrombin. Data represent means of 4-6 donors \pm standard error (SE). The effect of five different concentrations of the tested fraction $(0.5,1,5,10$, and $50 \mu \mathrm{g} / \mathrm{mL}$ ) was statistically significant according to ANOVA $I$ test, $p<0.05$ for concentrations 5,10 , and $50 \mu \mathrm{g} / \mathrm{mL}$ (resting platelets); $p<0.05$ for concentrations $1,5,10$, and $50 \mu \mathrm{g} / \mathrm{mL}$ (platelets activated by thrombin); $p>0.05$ for concentration $0.5 \mu \mathrm{g} / \mathrm{mL}$ (resting platelets and platelets activated by thrombin); $p>0.05$ for concentration $1 \mu \mathrm{g} / \mathrm{mL}$ (resting platelets).

The fraction's activity was concentration-dependent (Figure 3). At the highest concentration of the tested fraction $(50 \mu \mathrm{g} / \mathrm{mL})$, production of TBARS in resting and activated platelets was reduced by about $60 \%$ (Figure 3 ).

Analysis of the effect of $H$. rhamnoides phenolic extract (at concentrations between 0.5 and $50 \mu \mathrm{g} / \mathrm{mL}$ ) on the reduction of $\mathrm{O}_{2}{ }^{-\bullet}$ ) generation in resting blood platelets and platelets activated by thrombin is shown in Figure 4. All investigated concentrations of the phenolic fraction decreased $\mathrm{O}_{2}{ }^{-\bullet}$ production. The strongest inhibition was observed in platelets

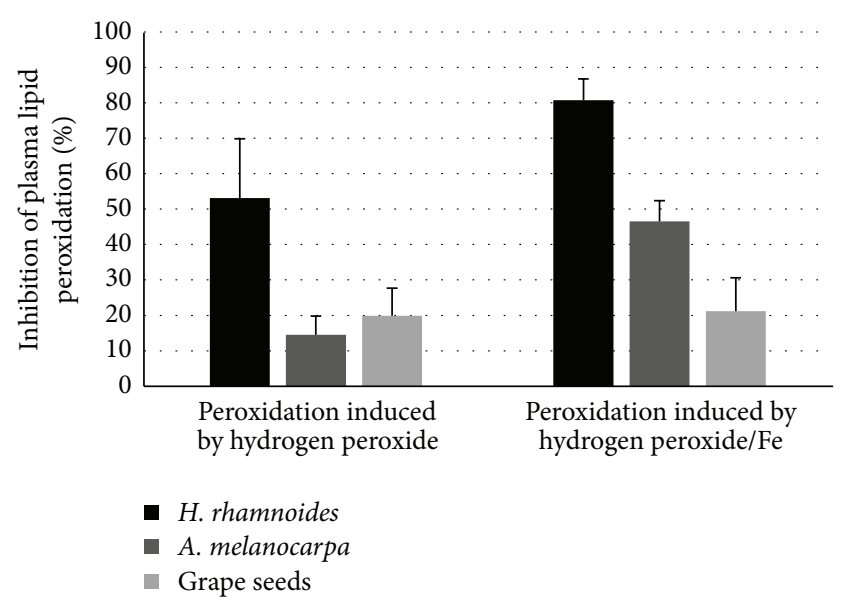

FIGURE 5: Effects of the phenolic fraction from fruits of $H$. rhamnoides ( $50 \mu \mathrm{g} / \mathrm{mL} ; 15 \mathrm{~min})$, A. melanocarpa extract $(50 \mu \mathrm{g} / \mathrm{mL}$, $15 \mathrm{~min})$, and grape seed extract ( $50 \mu \mathrm{g} / \mathrm{mL}, 15 \mathrm{~min}$ ) on plasma lipid peroxidation induced by $\mathrm{H}_{2} \mathrm{O}_{2}$ or $\mathrm{H}_{2} \mathrm{O}_{2} / \mathrm{Fe}$. The results represent 38 independent experiments and are expressed as means $\pm \mathrm{SE}$. The effects were significant according to ANOVA $I$ test, for peroxidation induced by $\mathrm{H}_{2} \mathrm{O}_{2}: H$. rhamnoides fraction-treated plasma versus A. melanocarpa extract-treated plasma ( $p<0.02)$; H. rhamnoides fraction-treated plasma versus grape seed extract-treated plasma $(p<0.05)$; for peroxidation induced by $\mathrm{H}_{2} \mathrm{O}_{2} / \mathrm{Fe}: H$. rhamnoides fraction-treated plasma versus $A$. melanocarpa extracttreated plasma $(p<0.01) ; H$. rhamnoides fraction-treated plasma versus grape seed extract-treated plasma $(p<0.01)$.

treated with the highest dose $(50 \mu \mathrm{g} / \mathrm{mL})$ of the fraction, reaching about $40 \%$ for resting platelets and about $55 \%$ for platelets activated by thrombin (Figure 4).

In comparative experiments, the phenolic fraction of sea buckthorn fruits (at the highest tested concentration, $50 \mu \mathrm{g} / \mathrm{mL}$ ) turned out to be more effective than $50 \mu \mathrm{g} / \mathrm{mL}$ Aronia extract or $50 \mu \mathrm{g} / \mathrm{mL}$ grape seed extract (Figures 5-7).

\section{Discussion}

Phenolic compounds are plant secondary metabolites with antioxidant properties. They play an important role in adsorbing and neutralizing reactive oxygen species. Moreover, phenols may act as chelators for the transition of metal ions $\mathrm{Fe}^{2+}, \mathrm{Fe}^{3+}$, and $\mathrm{Cu}^{2+}$ that are involved in the conversion of $\mathrm{H}_{2} \mathrm{O}_{2}$ into $\mathrm{OH}^{\bullet}$ and stimulation of lipid peroxidation [24]. Prooxidative or antioxidative activities of the phenolic fraction from fruits of $H$. rhamnoides and their biological significance remain unclear. Only few human experiments were found, which examine the effects of $H$. rhamnoides on the oxidative stress associated with cardiovascular diseases [25]. The used $H$. rhamnoides fraction from fruits was tested at a dose range of $0.5-50 \mu \mathrm{g} / \mathrm{mL}$, which corresponds to the physiological range of phenolic compounds in human plasma. Plasma and blood platelets were used in our in vitro study because they are vital components of hemostasis; moreover, oxidative stress in plasma and blood platelets may promote the development of cardiovascular diseases. In our experiments, addition of $\mathrm{H}_{2} \mathrm{O}_{2}$ or $\mathrm{H}_{2} \mathrm{O}_{2}$ /Fe to human plasma 


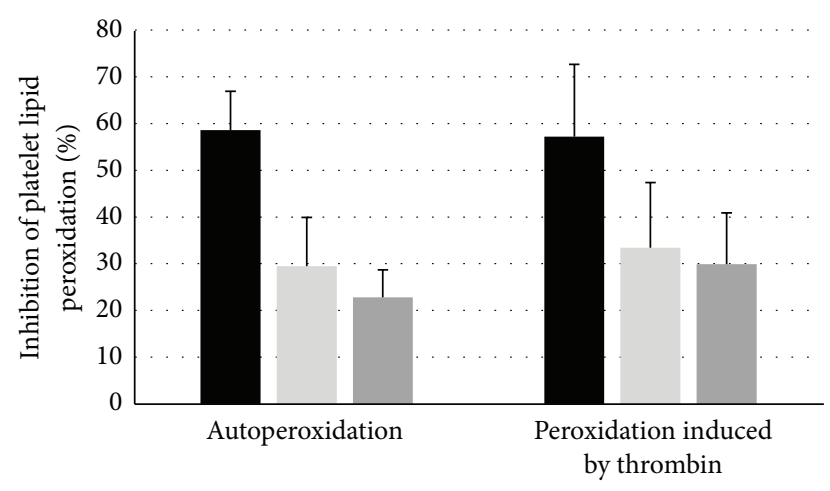

- H. rhamnoides

- A. melanocarpa

- Grape seeds

FIGURE 6: Effects of the phenolic fraction from fruits of $H$. rhamnoides ( $50 \mu \mathrm{g} / \mathrm{mL} ; 15 \mathrm{~min})$, A. melanocarpa extract $(50 \mu \mathrm{g} / \mathrm{mL}$, $15 \mathrm{~min})$, and grape seed extract $(50 \mu \mathrm{g} / \mathrm{mL}, 15 \mathrm{~min})$ on autoperoxidation of blood platelets and platelet lipid peroxidation induced by thrombin. The results represent 3-4 independent experiments and are expressed as means \pm SE. The effects were significant according to ANOVA $I$ test, for autoperoxidation: $H$. rhamnoides fractiontreated platelets versus A. melanocarpa extract-treated platelets $(p<$ $0.01) ; H$. rhamnoides fraction-treated platelets versus grape seed extract-treated platelets $(p<0.01)$; for peroxidation induced by thrombin: $H$. rhamnoides fraction-treated platelets versus $A$. melanocarpa extract-treated platelets $(p<0.05) ; H$. rhamnoides fraction-treated platelets versus grape seed extract-treated platelets $(p<0.05)$.

resulted in a significant increase in the level of oxidative stress (measured by TBARS or the level of carbonyl groups). Our findings demonstrate for the first time the antioxidative properties of the phenolic fraction from $H$. rhamnoides fruits. The tested fraction significantly inhibited plasma lipid peroxidation induced by $\mathrm{H}_{2} \mathrm{O}_{2}$ or $\mathrm{H}_{2} \mathrm{O}_{2} / \mathrm{Fe}$.

Protein carbonyl formation is a relatively stable biomarker of oxidative stress, as a result of amino acid modifications (i.e., Lys, Arg, Cys, Thr, or Pro). Protein carbonylation is the nonenzymatic addition of aldehydes or ketones to specific amino acid residues. In our experiments, the phenolic fraction from fruits of $H$. rhamnoides decreased the concentration of carbonyl groups in plasma proteins treated with $\mathrm{H}_{2} \mathrm{O}_{2}$ or $\mathrm{H}_{2} \mathrm{O}_{2} / \mathrm{Fe}$. Our findings show for the first time that the phenolic fraction of $H$. rhamnoides fruits has inhibitory action not only on human plasma lipid peroxidation, but also on carbonylation of human plasma proteins. Upadhyay et al. [9] observed the said antioxidant effect of H. rhamnoides leaves. Aqueous and hypoalcoholic extracts of H. rhamnoides had cytoprotective activity against hydrogen peroxide and hypoxanthine-xanthine oxidase-stimulated damage to BHK21 cell line. Maheshwari et al. [26] demonstrated that the phenolic-rich fraction of $H$. rhamnoides leaves has potent antioxidant activity, prevents oxidative damage to lipids and proteins, and affords significant protection against $\mathrm{CCl}_{4}$ stimulated oxidative liver damage in Sprague Dawley rats. Based on the results of Khan et al. [27], it can be shown

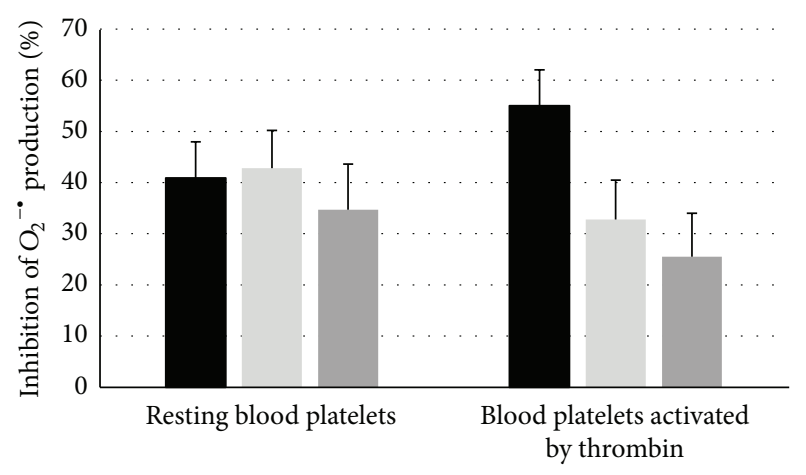

$$
\begin{aligned}
& \text { - H. rhamnoides } \\
& \text { - A. melanocarpa } \\
& \text { Grape seeds }
\end{aligned}
$$

FIgURE 7: Effects of the phenolic fraction from fruits of $H$. rhamnoides ( $50 \mu \mathrm{g} / \mathrm{mL} ; 15 \mathrm{~min})$, A. melanocarpa extract $(50 \mu \mathrm{g} / \mathrm{mL}$, $15 \mathrm{~min})$, and grape seed extract $(50 \mu \mathrm{g} / \mathrm{mL}, 15 \mathrm{~min})$ on $\mathrm{O}_{2}^{-{ }^{-\bullet}}$ generation in resting blood platelets and blood platelets activated by thrombin. The results represent 3-6 independent experiments and are expressed as means \pm SE. The effects were significant according to ANOVA $I$ test, for resting platelets: $H$. rhamnoides fractiontreated platelets versus A. melanocarpa extract-treated platelets $(p>$ $0.05) ; H$. rhamnoides fraction-treated platelets versus grape seed extract-treated platelets $(p>0.05)$; for peroxidation induced by thrombin: $H$. rhamnoides fraction-treated platelets versus $A$. melanocarpa extract-treated platelets $(p<0.05)$; H. rhamnoides fraction-treated platelets versus grape seed extract-treated platelets $(p<0.05)$.

that $H$. rhamnoides leaf extract ameliorates gamma radiationmediated DNA damage and hepatic alterations.

Another set of our experiments showed that the $H$. rhamnoides phenolic fraction could effectively reduce lipid peroxidation in blood platelets. After $15 \mathrm{~min}$ preincubation of platelets with the tested fraction, the amounts of TBARS in resting and thrombin-stimulated platelets were reduced. The results suggest that the tested extract may also play a role in modulating blood platelet activation by interfering with the metabolism of arachidonic acid, in which cyclooxygenase or lipoxygenase takes part. In addition, blood platelets themselves can produce several ROS, including the superoxide anion, hydrogen peroxide, and hydroxyl radical $[22,28]$. It has been demonstrated that ROS participate in signal transmission. Changes in blood platelet responsiveness to a strong physiological agonist, thrombin, were observed in the present in vitro study, when platelets were preincubated with the H. rhamnoides fraction. Because cyclooxygenase is involved in ROS generation in platelets, it seems possible that the tested fraction may modulate ROS production by interfering with the metabolism of arachidonic acid, in which this enzyme takes part. However, results obtained by Eccleston et al. [11] showed that there were no significant changes in blood platelet aggregation between treatment groups (twenty healthy male volunteers were given either a placebo or $H$. rhamnoides juice for 8 weeks). On the other hand, H. rhamnoides seed oil has antiatherogenic and 
cardioprotective activity $[5,29]$. Moreover, an antihypertensive effect of flavones extracted from seed residues of $H$. rhamnoides in sucrose-fed rats was observed by Pang et al. [1].

Additionally, we studied the effect of the tested fraction on $\mathrm{O}_{2}{ }^{-\bullet}$ production in resting blood platelets. The fraction exhibited antioxidant activity not only in blood platelets activated by thrombin, but also in resting platelets. Our results also demonstrated that the phenolic fraction from H. rhamnoides fruits had stronger antioxidant activity than extracts from Aronia berries and grape seeds. It may be supposed that differences in their chemical profiles (the total concentration of phenolics for Aronia berry extract, $309.6 \mathrm{mg} / \mathrm{g}$ of extract; the total concentration of phenolics for grape seed extract, $500 \mathrm{mg} / \mathrm{g}$ of extract; the total concentration of phenolics for $H$. rhamnoides fruits fraction, $242.69 \mathrm{mg} / \mathrm{g}$ of extract) may explain the stronger action of the $H$. rhamnoides fraction. The major phenolic compounds of $H$. rhamnoides fraction are the flavonols. Flavonol glycosides, isorhamnetin 3-O-hexosidedeoxyhexoside and isorhamnetin 3-O-hexoside, were present in the highest concentrations. Teleszko et al. [30] also identified in $H$. rhamnoides fruits flavonols as the major group of phenolic compounds. We suppose that these phenolic compounds may act as main antioxidants in $H$. rhamnoides fraction. It is important to note that other tested extracts have not these compounds. Therefore, the effects of various phenolic compounds, that is, isorhamnetin 3-O-hexosidedeoxyhexoside and isorhamnetin 3-O-hexoside, which may be responsible for antioxidative and antiplatelet activity, remain to be investigated. Moreover, results of Luo et al. [31] indicate that isorhamnetin inhibited atherosclerotic plaque development by phosphatidylinositol 3-kinase/protein kinase $B$ activation and heme oxygenase induction.

Our present results show that $H$. rhamnoides fraction, like Aronia berries extract and grape seeds extract, displays a multiple effect that is on blood platelets. H. rhamnoides fraction may modulate the signal transduction in different, sometimes opposite, pathways. Firstly, it causes changes in reactive oxygen species level in platelets. Secondly, it modulates the arachidonic acid metabolism (probably by the inhibition of cyclooxygenase activity). However, it may also change the expression of receptors or activity of various enzymes involved in platelet activation.

The fraction of $H$. rhamnoides fruits in comparison to a well-known Aronia berries may be a good source of active substances for pharmacological or cosmetic applications. From an economic point of view, it is true that $H$. rhamnoides fruits purchase price is about four times higher than Aronia berries price, but the yield per hectare of $H$. rhamnoides fruits is four times larger at the same time. Our preliminary studies show that the $H$. rhamnoides leaves contain qualitatively the same compounds as their fruits. As fruits are harvested together with leaves and branches, on which they grow, there is a possibility of obtaining additionally phenolic compounds from leaves as a production waste.

Our study demonstrates that $H$. rhamnoides fruits could be used as a natural source of antioxidants and compounds with antiplatelet activity to prevent and/or cure disorders associated with oxidative stress and changes in platelet activation. Moreover, it gives hope for the development of new diet supplements, and so experiments with the fruit of $H$. rhamnoides should be continued. We plan to identify individual or groups of phenolic compounds, which are responsible for the antioxidant and antiplatelet properties of $H$. rhamnoides fraction.

\section{Conflict of Interests}

The authors declare no conflict of interests.

\section{Acknowledgments}

This work was supported by Grant 506/1136 from the University of Łódź. The authors would also like to thank Katarzyna Lipska and Marek Pawlonka from VF-Concept company (Janów Lubelski, Poland) for providing the sea buckthorn fruits.

\section{References}

[1] X. Pang, J. Zhao, W. Zhang et al., "Antihypertensive effect of total flavones extracted from seed residues of Hippophae rhamnoides L. in sucrose-fed rats," Journal of Ethnopharmacology, vol. 117, no. 2, pp. 325-331, 2008.

[2] T. Cheng and T. Li, "Protective action of seed oil of Hippophae rhamnoides L. (HR) against experimental liver injury in mice," Zhonghua Yufang Yixue Zazhi, vol. 26, pp. 227-229, 1992.

[3] X. Gao, M. Ohlander, N. Jeppsson, L. Björk, and V. Trajkovski, "Changes in antioxidant effects and their relationship to phytonutrients in fruits of sea buckthorn (Hippophae rhamnoides L.) during maturation," Journal of Agricultural and Food Chemistry, vol. 48, no. 5, pp. 1485-1490, 2000.

[4] H. Sleyman, L. Demirezer, M. E. Bykokuroglu et al., "Antiulcerogenic effect of Hippophae rhamnoides L.", Phytotherapy Research, vol. 15, no. 7, pp. 625-627, 2001.

[5] P. Malinowska and B. Olas, "Sea buckthorn-valuable plant for health," Kosmos, no. 1, 2016.

[6] S. Shivapriya, K. Ilango, and G. P. Dubey, "Evaluation of antioxidant and neuroprotective effect of Hippophae rhamnoides (L.) on oxidative stress induced cytotoxicity in human neural cell line IMR32," Saudi Journal of Biological Sciences, vol. 22, no. 5, pp. 645-650, 2015.

[7] L. Rongsen, "Seabuckthorn: a multipurpose plant species for fragile mountains," ICIMOD Occasional Paper 20, International Centre for Integrated Mountain Development, Kathmandu, Nepal, 1992.

[8] V. B. Guliyev, M. Gul, and A. Yildirim, "Hippophae rhamnoides L.: chromatographic methods to determine chemical composition, use in traditional medicine and pharmacological effects," Journal of Chromatography B: Analytical Technologies in the Biomedical and Life Sciences, vol. 812, no. 1-2, pp. 291-307, 2004.

[9] N. K. Upadhyay, R. Kumar, M. S. Siddiqui, and A. Gupta, "Mechanism of wound-healing activity of Hippophae rhamnoides L. leaf extract in experimental burns," Evidence-Based Complementary and Alternative Medicine, vol. 2011, Article ID 659705, 9 pages, 2011.

[10] F. Yang, J. Quan, T. Y. Zhang, and Y. Ito, "Multidimensional counter-current chromatographic system and its application," Journal of Chromatography A, vol. 803, no. 1-2, pp. 298-301, 1998. 
[11] C. Eccleston, Y. Baoru, R. Tahvonen, H. Kallio, G. H. Rimbach, and A. M. Minihane, "Effects of an antioxidant-rich juice (sea buckthorn) on risk factors for coronary heart disease in humans," Journal of Nutritional Biochemistry, vol. 13, no. 6, pp. 346-354, 2002.

[12] Y. Liu, Y.-S. Lian, Y.-L. Wang, M.-H. Li, and P.-G. Xiao, "Review of research and development and significant effect of Hippophae rhamnoides," Zhongguo Zhongyao Zazhi, vol. 39, no. 9, pp. 15471552, 2014.

[13] M. Kędzierska, B. Olas, B. Wachowicz et al., "An extract from berries of aronia melanocarpa modulates the generation of superoxide anion radicals in blood platelets from breast cancer patients," Planta Medica, vol. 75, no. 13, pp. 1405-1409, 2009.

[14] B. Olas, B. Wachowicz, P. Nowak et al., "Studies on antioxidant properties of polyphenol-rich extract from berries of Aronia melanocarpa in blood platelets," Journal of Physiology and Pharmacology, vol. 59, no. 4, pp. 823-835, 2008.

[15] B. Olas, B. Wachowicz, A. Tomczak, J. Erler, A. Stochmal, and W. Oleszek, "Comparative anti-platelet and antioxidant properties of polyphenol-rich extracts from: berries of Aronia melanocarpa, seeds of grape and bark of Yucca schidigera in vitro," Platelets, vol. 19, no. 1, pp. 70-77, 2008.

[16] D. Rösch, A. Krumbein, C. Mügge, and L. W. Kroh, "Structural investigations of flavonol glycosides from sea buckthorn (Hippophäe rhamnoides) pomace by NMR spectroscopy and HPLCESI-MS n," Journal of Agricultural and Food Chemistry, vol. 52, no. 13, pp. 4039-4046, 2004.

[17] R. Fang, N. C. Veitch, G. C. Kite, E. A. Porter, and M. S. J. Simmonds, "Enhanced profiling of flavonol glycosides in the fruits of sea buckthorn (Hippophae rhamnoides)," Journal of Agricultural and Food Chemistry, vol. 61, no. 16, pp. 3868-3875, 2013.

[18] B. Walkowiak, E. Michalak, W. Koziolkiewicz, and C. S. Cierniewski, "Rapid photometric method for estimation of platelet count in blood plasma or platelet suspension," Thrombosis Research, vol. 56, no. 6, pp. 763-766, 1989.

[19] B. Wachowicz, "Adenine nucleotides in thrombocytes of birds," Cell Biochemistry and Function, vol. 2, no. 3, pp. 167-170, 1984.

[20] S. M. Nabavi, S. F. Nabavi, S. Eslami, and A. H. Moghaddam, "In vivo protective effects of quercetin against sodium fluorideinduced oxidative stress in the hepatic tissue," Food Chemistry, vol. 132, no. 2, pp. 931-935, 2012.

[21] B. Olas, H. M. Żbikowska, B. Wachowicz, T. Krajewski, A. Buczyński, and A. Magnuszewska, "Inhibitory effect of resveratrol on free radical generation in blood platelets," Acta Biochimica Polonica, vol. 46, no. 4, pp. 961-966, 1999.

[22] B. Wachowicz, B. Olas, H. M. Zbikowska, and A. Buczynski, "Generation of reactive oxygen species in blood platelets," Platelets, vol. 13, no. 3, pp. 175-182, 2002.

[23] I. Dalle-Donne, R. Rossi, D. Giustarini, A. Milzani, and R. Colombo, "Protein carbonyl groups as biomarkers of oxidative stress," Clinica Chimica Acta, vol. 329, no. 1-2, pp. 23-38, 2003.

[24] D. Nowak, "Antioxidant plant polyphenols and cognitive disorders," in Oxidative Stress in Applied Basic Research and Clinical Practice, A. Dietrich-Muszalska, V. Chauhan, and S. Grignon, Eds., Studies on Psychiatric Disorders, pp. 521-553, Humana Press, 2015.

[25] M. Sayegh, C. Miglio, and S. Ray, "Potential cardiovascular implications of Sea Buckthorn berry consumption in humans," International Journal of Food Sciences and Nutrition, vol. 65, no. 5, pp. 521-528, 2014.
[26] D. T. Maheshwari, M. S. Yogendra Kumar, S. K. Verma, V. K. Singh, and S. N. Singh, "Antioxidant and hepatoprotective activities of phenolic rich fraction of Seabuckthorn (Hippophae rhamnoides L.) leaves," Food and Chemical Toxicology, vol. 49, no. 9, pp. 2422-2428, 2011.

[27] A. Khan, K. Manna, D. K. Das et al., "Seabuckthron (Hippophae rhamnoides L.) leaf extract ameliorates the gamma radiation mediated DNA damage and hepatic alterations," Indian Journal of Experimental Biology, vol. 52, no. 10, pp. 952-964, 2014.

[28] B. Jahn and G. M. Hansch, "Oxygen radical generation in human platelets: dependence on 12-lipoxygenase activity and on the glutathione cycle," International Archives of Allergy and Immunology, vol. 93, no. 1, pp. 73-79, 1990.

[29] M. Basu, R. Prasad, P. Jayamurthy, K. Pal, C. Arumughan, and R. C. Sawhney, "Anti-atherogenic effects of seabuckthorn (Hippophaea rhamnoides) seed oil," Phytomedicine, vol. 14, no. 11, pp. 770-777, 2007.

[30] M. Teleszko, A. Wojdyło, M. Rudzińska, J. Oszmiański, and T. Golis, "Analysis of lipophilic and hydrophilic bioactive compounds content in sea buckthorn (Hippophae rhamnoides L.) berries," Journal of Agricultural and Food Chemistry, vol. 63, no. 16, pp. 4120-4129, 2015.

[31] Y. Luo, G. Sun, X. Dong et al., "Isorhamnetin attenuates atherosclerosis by inhibiting macrophage apoptosis via PI3K/AKT activation and HO-1 induction," PLOS ONE, vol. 10, no. 3, Article ID e0120259, 19 pages, 2015. 


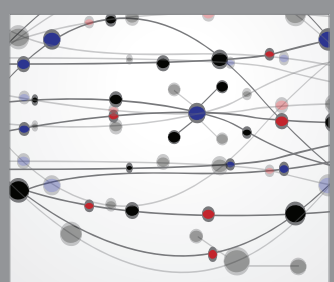

The Scientific World Journal
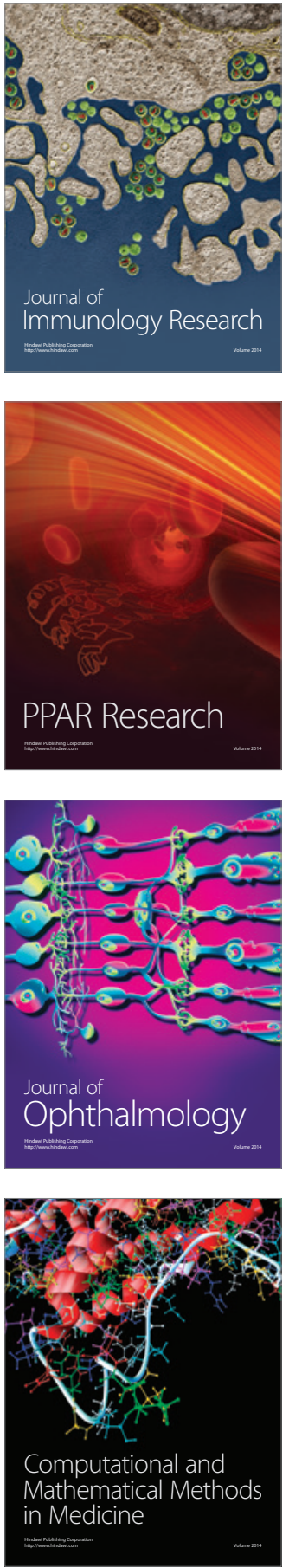

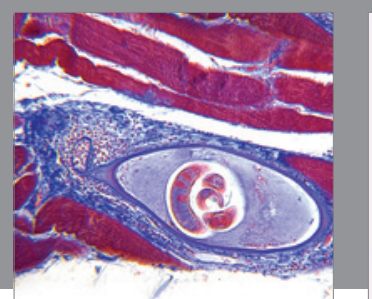

Gastroenterology Research and Practice

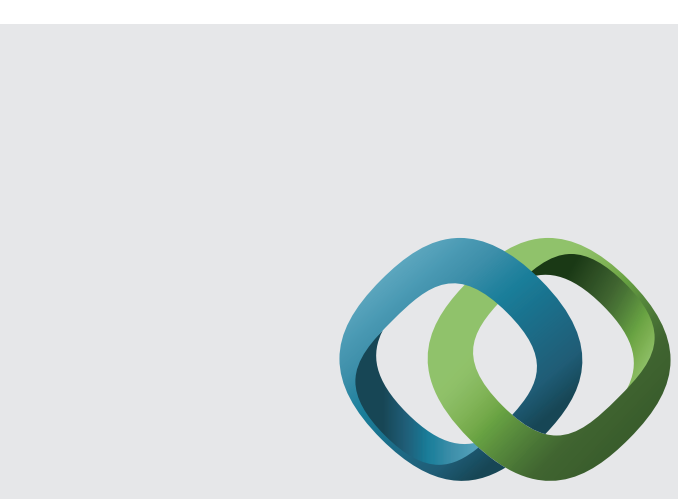

\section{Hindawi}

Submit your manuscripts at

http://www.hindawi.com
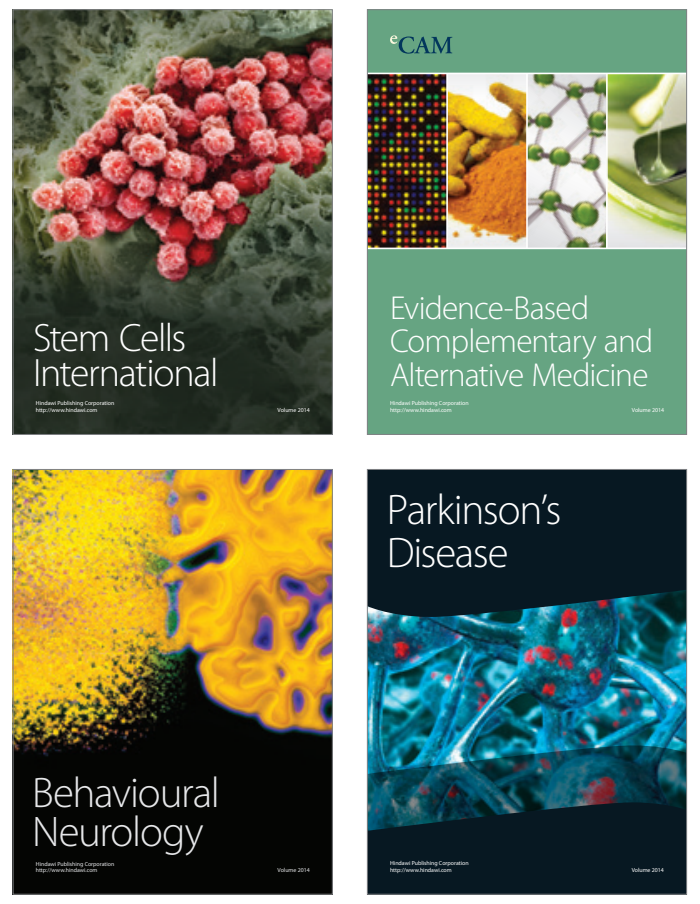
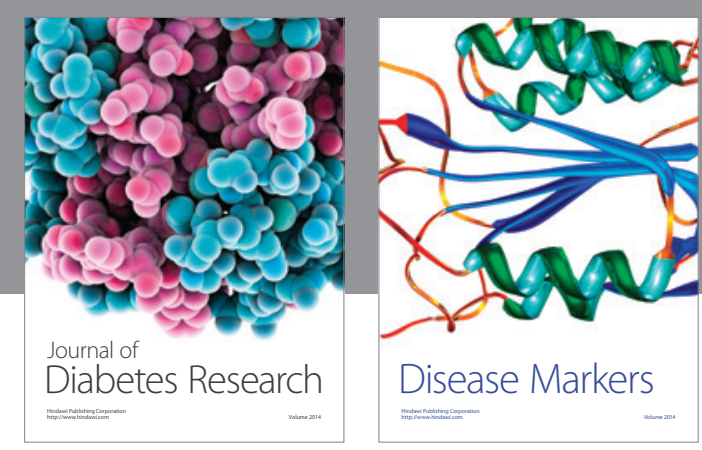

Disease Markers
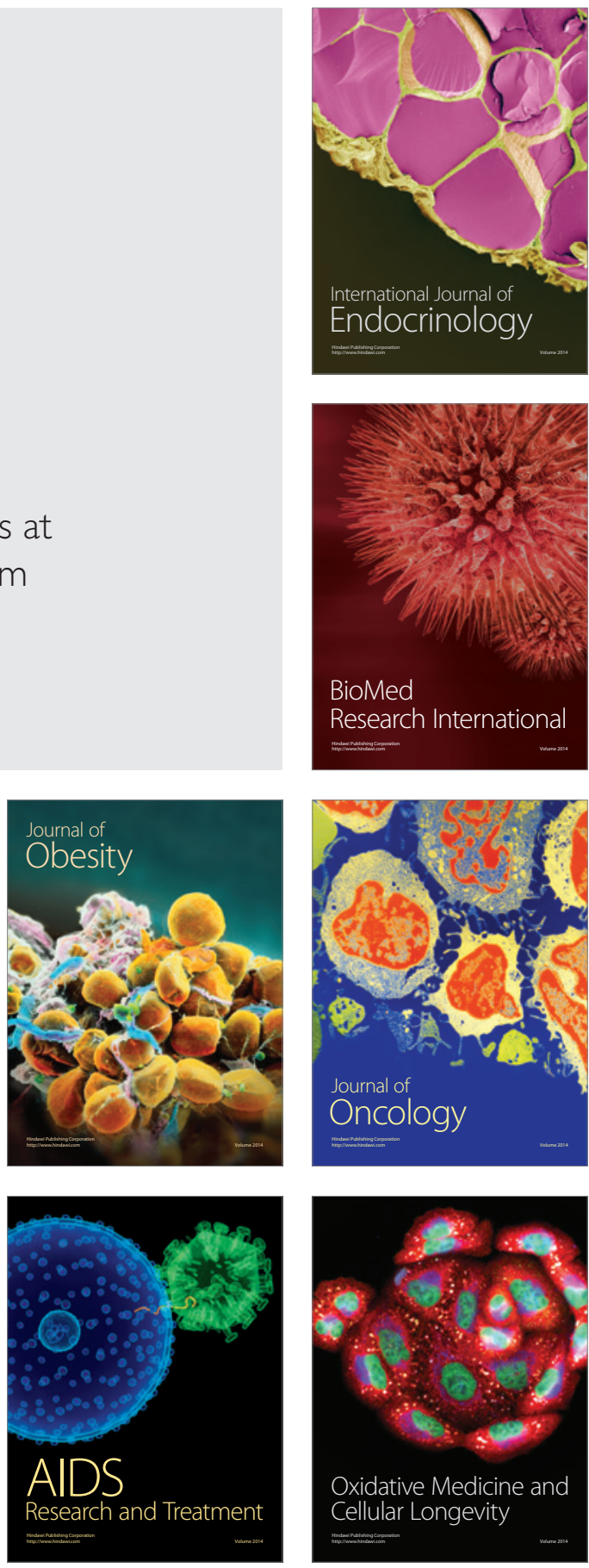